\title{
Inclusão Escolar: Concepções dos Profissionais da Escola sobre o Surdo e a Surdez
}

\author{
Carine Mendes da Silva \\ Universidade de Brasília, DF, Brasil. \\ Danielle Sousa da Silva \\ Universidade de Brasília, DF, Brasil.
}

\author{
Rosa Monteiro \\ Universidade de Brasília, DF, Brasil. \\ Daniele Nunes Henrique Silva \\ Universidade de Brasília, DF, Brasil.
}

Resumo: A inclusão educacional de surdos tem sido frequentemente debatida, especialmente, pela condição bilíngue e bicultural dos alunos, que exige práticas diferenciadas de ensino que partem da Libras. O objetivo do estudo foi entender o que os profissionais da escola dizem sobre o papel dessa língua. Participaram: a diretora, o supervisor pedagógico, a coordenadora de linguagens e códigos, a coordenadora de humanas, o coordenador de exatas, o professor de português como segunda língua, a professora da sala de recursos e a intérprete de Libras. O trabalho de campo foi realizado em uma escola de ensino médio da rede pública do Distrito Federal. O método de pesquisa baseou-se construção de dados organizados a partir de entrevistas semiestruturadas, seguindo os pressupostos teóricos do materialismo histórico dialético. Desta forma, os significados compartilhados entre o pesquisador e o entrevistador compuseram um texto para a análise da palavra e os significados que lhes são atribuídos, considerando as condições materiais em que é produzida. Depois de transcritas, as entrevistas formaram um texto em que a palavra é considerada como uma unidade de análise categórica. Das análises depreendeu-se um eixo intitulado: a concepção dos profissionais sobre o surdo e a surdez. As bases conclusivas do estudo apontam que há uma lacuna na formação profissional dos educadores no que tange as especificidades dos alunos.

Palavras-chave: Inclusão, Bilinguismo, Surdos, Educadores.

\section{School Inclusion: Conceptions of School Professionals}

\section{About the Deaf and the Deafness}

\begin{abstract}
The inclusion of deaf students has often been debated, especially for the bilingual and bicultural conditions of students who require specific teaching practices based on sign language. The objective of the study was to understand the point of view of educators on the role of this language. Eight professionals participated: the school director, the educational supervisor, the Brazilian Portuguese coordinator, the human sciences coordinator, the exact sciences coordinator, the teacher of Brazilian Portuguese as a second language, the resources room teacher and an interpreter of Brazilian Sign Language. The fieldwork was conducted at a public high school in Brazil's Federal District. The method of the research was based on the construction of data organized from semi-structured interviews, following the theoretical assumptions of the dialectical historical materialism. In this way, the meanings shared between the researcher and interviewer composed a text for the analysis of the word and the meanings attributed to it, considering the material conditions in which it is produced. After being transcribed, the interviews formed a text in which the word is considered as a categorical unit of analysis. From the data analysis one category emerged: The professionals' conception about the deaf student and the deafness. The conclusive bases of the study point out that there is a gap in the professional formation of educators regarding the specificities of students.
\end{abstract}

Keywords: Inclusion, Bilingualism, Deaf, Educators. 


\title{
Inclusión Escolar: Concepciones de los Profesionales de la Escuela sobre el Sordo y la Sordera
}

\begin{abstract}
Resumen:La inclusión educacional de sordos tiene sido frecuentemente debatida, en especial, por la condición bilingüe y bicultural de los alumnos, que exigen prácticas diferenciadas de enseñanza que proceden de las Libras. El objetivo del estudio fue entender lo que los profesionales de la escuela dicen acerca del papel de esta lengua. Participaron: el director, el supervisor pedagógico, la coordinadora de lenguajes y códigos, la coordinadora de humanas, el coordinador de exactas, el profesor de portugués como segunda lengua, la profesora del aula de recursos y la intérprete de Libras. El trabajo de campo fue realizado en una escuela de enseñanza media de la red pública de Distrito Federal (Brazil). El método de la investigación se basó en la construcción de datos organizados a partir de entrevistas semiestructuradas, siguiendo los presupuestos teóricos del materialismo histórico dialéctico. De esta forma, los significados compartidos entre el investigador y el entrevistador compusieron un texto para el análisis de la palabra y los significados que se les atribuyen, considerando las condiciones materiales en que se produce. Después de transcritas, las entrevistas formaron un texto en el que la palabra es considerada como una unidad de análisis categórica. De los análisis se desprendió un eje intitulado: la concepción de los profesionales acerca del sordo y la sordera. Las bases conclusivas del estudio apuntan que hay una brecha en la formación profesional de los educadores en lo que se refiere a las especificidades de los alumnos.
\end{abstract}

Palabras clave: Inclusión, Bilingüismo, Sordos, Educadores.

\section{Introdução}

Um dos temas mais debatidos no âmbito educacional brasileiro é a política de educação inclusiva expressa na Lei de Diretrizes e Bases da Educação Nacional-LDB de 1996 que apregoa por um único sistema escolar para todos. Nesse sentido, a inclusão escolar define a obrigatoriedade de as escolas públicas oferecerem o acesso à educação de qualidade para todos os alunos, na qual suas particularidades, sejam elas de cunho étnico, religioso, cultural e/ou de caráter orgânico e psicológico, sejam respeitadas no contexto escolar (Lopes, Silvana, Vieira, \& Oliveira, 2016; Ribeiro, 2014).

Uma marca de que a implementação da inclusão atinge o público alvo é a crescente do número de alunos matriculados nas escolas, conforme visto em Silva (2014). Por outro lado, pesquisas têm concluído que este aumento não significa o sucesso da inclusão educacional, pois, há uma defasagem escolar, em termos de aprendizagem, verificada em muitos estudos sobre os alunos com necessidades educacionais especiais (Kassar, 2011; Lopes et al., 2016; Silva, Silva e Silva, 2013).

Quadros (2003) aponta como lacuna a falta de direcionamento das políticas públicas de educação inclusiva, no que se refere a uma discussão mais adensada sobre os desdobramentos culturais e linguísticos obser- vados na inserção dos alunos com necessidades educacionais especiais em turmas regulares. A autora aponta que a experiência de estudantes surdos no contexto escolar é relevante nesse contexto por ser um grupo com características singulares relacionadas ao curso de seu desenvolvimento que é pelo canal visuo-espacial (Kelman, Silva, Amorim, Monteiro, \& Azevedo, 2011).

O desenvolvimento e o processo de aprendizagem do surdo deveriam estar articulados à aprendizagem pela Língua Brasileira de Sinais (Libras); à língua natural dos surdos e a de sua comunidade (Silva, 2014; Soares, Andrade, \& Soares, 2016). Tal língua suscita possibilidades de interpretação, interação com o outro, completamente distinta da maioria ouvinte, sendo fundamental para inserir o surdo nos processos dialógicos do meio em que vivem, ao mesmo tempo em que define a sua construção identitária (Lacerda, 2006).

No âmbito dessas discussões, Ribeiro (2014) afirma que a inclusão do surdo não pode estar alheia a sua condição bilíngue e bicultural, pautada na Libras, como primeira língua e na Língua Portuguesa (na modalidade escrita), em segundo plano. Na língua de sinais reside, portanto, o núcleo investigativo dos desafios relacionadas a inclusão escolar do surdo, conforme será visto adiante. 


\section{A língua de sinais e os desafios da educação de surdos}

A língua de sinais é pautada na dimensão espacial, com estruturas semântica, sintática e gramatical completas, apesar de essencialmente distintas das línguas escritas e faladas (Sacks, 2010). As características dessa língua, especialmente no tocante à ausência de sonoridade, constituem de forma singular os processos de significação dos indivíduos que a utilizam (Souza, 2003).

Nesse sentido, a língua de sinais delineia-se elementar para o desenvolvimento do surdo em todas as esferas (sociolinguística, educacional, cultural, entre outros). Pesquisadores da área da surdez (Lacerda, Albres e Drago, 2013; Lodi, 2013; Slomski, 2010), cientes da essencialidade da língua de sinais, apontam conflitos vivenciados pelos surdos nas situações de inclusão escolar, como por exemplo, a ausência de profissionais bilíngues e decorrente privação dos estudantes sobre os conteúdos e vivências em classe.

Nesse contexto, um dos maiores desafios impostos aos surdos, diante de uma escola pensada e programada para os ouvintes, diz respeito a sua escolaridade. Enfim, como não fracassar? Como aprender?

Para Santana e Bergamo (2005), a língua de sinais é o fator que distingue o indivíduo surdo do ouvinte, aparecendo como elemento central para o desenvolvimento do surdo. Entretanto, essa mesma língua se constitui, contraditoriamente, como fator de discriminação. Não raras vezes, o surdo vivencia situações de fracasso dentro da escola, resultante das relações estabelecidas com a maioria ouvinte e dos embates desdobrados das questões linguísticas (Lacerda, 2006).

Segundo Silva (2014) as escolas devem assegurar o trabalho centralizado na Libras e nas implicações dela para a aprendizagem, pois essa língua traz impactos para o modo de constituição do surdo e diz respeito, centralmente, aos aspectos referentes a cultura surda (Beltrami, \& Moura, 2015; Ribeiro, 2014). Se nos estabelecimentos de ensino, por ventura, tais aspectos forem desprezados, a relação do surdo com os pares pode gerar conflitos de ordens psicológicas e sociais, como também, o fracasso escolar desses sujeitos. Quadros (2003), ao discutir essa situação, caracteriza a sensação de alguns estudantes surdos em sala de aula: silenciados dentro do grupo.

O silêncio, na verdade, representa o sentimento de vazio relatado por muitos surdos quando descrevem a experiência de aprendizagem pouco satisfa- tória que conseguiram após anos frequentando uma escola (Lacerda, 2006). A inclusão, a qualquer custo, negligencia questões fundamentais referentes à cultura, linguagem, dinâmicas de comunidades minoritárias pouco enaltecidas no processo educacional. (Goés, \& Lacerda, 2000).

As políticas de educação inclusiva fomentadas no início da década de 1990, como a Câmara técnica denominada "O surdo e a Língua de Sinais", promovida pela Coordenadoria Nacional para Integração da Pessoa Portadora de Deficiência (Corde), iniciou fortes discussões sobre a importância da Libras como língua oficial dos surdos que, portanto, deve ser compulsória nos ambientes escolares. Vale salientar que participaram desse fórum, pesquisadores de Universidades públicas e privadas, e estudiosos da língua de sinais que, na ocasião, representavam os interesses da comunidade surda. Segundo Lodi (2013), a Câmara apontou a necessidade da formação de profissionais tradutores e intérpretes de Libras, amparando discussões sobre projetos de leis para o surdo.

Ressalta-se a importância da participação dos líderes de movimentos surdos e educadores que reuniram-se, no ano de 1999, no pré-congresso antecedente ao V Congresso Latino-Americano de Educação Bilíngue para Surdos, com o objetivo de ampliar o debate em torno dos seguintes temas: identidades surdas, cultura surda e educação de surdos. O pré-congresso desse evento, foi desenvolvido e realizado somente por pessoas surdas, o que demarcou uma ação política que buscava dar visibilidade e $v o z$ a comunidade surda para tomar decisões no que tange à cultura, à filosofia educacional, à língua de sinais entre outros. Os resultados dessa mobilização foram registrados no documento intitulado "A Educação que nós surdos queremos” (FENEIS, 1999), fonte de instrução para muitas escolas de surdos, no Brasil (Thoma, \& Klein, 2010).

Essa ação política demonstrou os esforços dos defensores dos direitos dos surdos e da comunidade surda para indicar a necessidade da criação de escolas exclusivas para surdos. Uma escola orientada a promover um lugar de encontro para o desenvolvimento da identidade surda e articulação dos processos educacionais comuns a essa minoria linguística. (FENEIS, 1999). Nesse contexto, o documento supracitado traz especificidades do ensino bilíngue exigido pela comunidade surda. Destaca-se, nas reivindicações, a preferência por uma escola exclusiva, voltada especial- 
mente para o ensino desse público, fator que demarca a dissonância entre a política apregoada na Lei de Diretrizes e bases da Educação Nacional (LDBEN, Lei No9.394, 1996) a necessidade desse alunado.

Nesse interim, o documento recomenda que o suporte tecnológico e docente especializados para o ensino de surdos (que se amparam exclusivamente em experiências imagéticas) não deve ser incluído em escolas regulares, pois, apenas, as escolas especializadas para esse tipo de atendimento poderiam suprir esse quesito. Complementa-se, também, que no caso de impossibilidade de estruturação das escolas exclusivas, a inserção de alunos surdos em classes especiais, na rede regular, deve ocorrer pelo entendimento de que eles possuem uma cultura, língua e comunidade distinta e, portanto, não são deficientes.

Essas reivindicações e as lutas ideológicas marcadas nos movimentos sociais, promovidos pelos militantes da surdez, repercutiram de forma intensa nas políticas educacionais para esse público, fortalecendo o debate sobre os direitos desses sujeitos, em especial, o reconhecimento da língua de sinais. Desse modo, em 2001, o Plano Nacional de Educação, documento relevante no cenário da educação inclusiva, indicou a formulação de propostas para a organização do ensino da Libras para alunos surdos e, posteriormente, se possível, para seus familiares e profissionais envolvidos no processo educativo.

Esse movimento de luta para a efetiva implementação da Libras no ensino regular ganhou mais força a partir da Lei Federal no 10.436 (2002), que reconhece a Língua Brasileira de Sinais como meio legal de comunicação originada nas comunidades de pessoas surdas, do Brasil. Todos esses encaminhamentos relacionados à língua dos surdos, ocorridos nas últimas duas décadas, colaboraram para que a filosofia educacional baseada no bilinguismo obtivesse maior visibilidade na educação dessa comunidade (Kubaski, \& Moraes, 2009; Lodi, 2013).

O bilinguismo se define como condição para inserção nos processos dialógicos do meio em que vivem. Ou seja, a partir do desenvolvimento primário, via língua de sinais, acessar e se apropriar dos elementos culturais produzidos pela sociedade, bem como o português, concebido como segunda língua. À luz dessa proposta, as políticas educacionais inclusivas devem assegurar o direito dos surdos de partilharem de sua língua nas escolas públicas de ensino regular (Lacerda, Albres e Drago, 2013; Lodi, 2013).

\section{As propostas bilíngues para educação de surdos: desafios atuais}

Modelos pedagógicos pautados no bilinguismo se fortaleceram na última década no Brasil. O bilinguismo é responsável por transformações na concepção ideológica sobre o que é ser surdo, que sucederam formas organizativas de ensino mais pertinentes a esse público (Fernandes, \& Moreira, 2009; Svartholm, 2014). Por meio de diferentes modalidades de ensino e variadas interpretações sobre o que vem a ser bilinguismo, essa abordagem educacional aponta para composição de práticas educacionais que consideram a centralidade dos aspectos linguísticos e sociais para a cultura surda.

Investigações e debates científicos e comunitários de estudiosos e Surdos ativistas a favor da abordagem bilíngue (Dizeu, \& Caporali, 2005; Fernandes, \& Moreira, 2009; Lacerda, 2006) , impulsionaram políticas educacionais inclusivas que, tem incutido aos poucos, propostas para assegurar o direito dos surdos de receberem sua educação em língua de sinais, nas escolas públicas de ensino regular, no entanto, não existe um consenso sobre qual modelo bilíngue seja mais adequado, conforme será apontado neste artigo.

No Decreto 5.626/2005 e na Lei no 10.436/2002 há deliberações específicas sobre a formação de docentes bilíngues, instrutores surdos e intérpretes de Libras, no entanto a estruturação do bilinguismo nas práticas pedagógicas, mais precisamente as questões metodológicas, ainda se delineiam como um desafio (Silva et al., 2013).

Segundo Goldfeld (2002) e Santana (2007), apesar de não haver unanimidade na aplicação do bilinguismo na esfera educacional, observam-se dois modelos de materialização dessa filosofia: o primeiro aponta para a aprendizagem da língua de sinais e da língua oral/auditiva majoritária com a alfabetização na língua de sinais em segundo plano. O segundo, descarta a necessidade de aprendizagem da língua oral, priorizando que o surdo adquira a língua de sinais e a língua majoritária na modalidade escrita (Silva, \& Silva, 2016). Coexistem, portanto, dois modelos para a educação bilíngue dos surdos e formatos diferenciados de implementação deles nas escolas, como por exemplo: a) o professor bilíngue lecionando em Libras para os alunos surdos e b) professor regente lecionando em Língua Portuguesa acompanhado do intérprete de Libras (Fernandez, \& Rios, 1998; Lebedeff, 2010). Por isso, é importante evidenciar como as ações orientadas sob a ótica bilíngue têm sido sistematizadas no cotidiano dos estudantes. 
Nesse sentido, Quadros (2006) descreve a importância de se garantir, na matrícula desses estudantes, a oferta de intérpretes. Entretanto, a autora alerta que a presença desse profissional não fornece todas as condições que o aluno surdo requer. Quadros (2006) afirma que o trabalho de interpretação circula entre duas línguas, partindo da tradução do conteúdo em Português para a língua de sinais, que é, portanto, secundária no processo. Isto é, as estratégias de ensino são pensadas, a priori, na língua nativa, presumindo que: a) a tradução para a Libras é o suficiente para a aprendizagem e b) a presença de intérprete significa resguardar o direito linguístico dos surdos. Stumpf (2008) descreve como essas práticas de inclusão tem ocorrido e revela seus prejuízos:

As dinâmicas educacionais da sala de aula e da escola estão focalizadas na língua oral e na escrita da mesma. O aluno surdo, inserido no espaço educacional de alunos ouvintes, sem os suportes adequados, tenta se comportar como ouvinte. Sua Língua de Sinais aparece pouco e, desfigurada de sua cultura, não há sinais. Como esse aluno terá acesso aos conhecimentos, se sua questão linguística não está sendo observada e, menos ainda, seu pertencimento cultural? Como o surdo desenvolverá conhecimentos, se a escola apenas faz mínimas concessões e, em seu imaginário, ainda se vê como um deficiente que, por força da lei, a escola é obrigada a recebê-lo? As diretrizes para a educação dos surdos apontadas pelo MEC não chegaram na maioria das escolas que recebem surdos. Estas dizem não ter suficientes condições estruturais e o surdo fica mal atendido sem que ninguém se responsabilize (p. 23).

Tais concessões citadas em Stumpf (2008) referem-se, por exemplo, ao direito à um intérprete. Segundo Quadros (2006), o intérprete representa um mecanismo legal das políticas de inclusão para manter os estudantes surdos nas escolas regulares, considerando que o ensino ideal para essa clientela deveria ocorrer em escolas que utilizassem a Libras, como primeira língua. Contudo, mesmo com o auxílio do intérprete, incoerências ainda permeiam a vida escolar de crianças e jovens surdos. A barreira comunicativa não se delineia como fator único de limitação para a escolarização desse grupo.
Lacerda (2006) evidencia a experiência solitária vivenciada pelos surdos nas escolas inclusivas quando somente acompanhados por intérpretes. Muitas vezes, os surdos não estabelecem relações efetivas com os demais pares escolares, pois professores, companheiros de classe e funcionários são ouvintes. Esse fator compromete o aprofundamento de suas relações, que são resumidas em trocas básicas de informações, por conta da não compatibilidade linguística.

Nesse sentido, o papel desempenhado pelo intérprete se delineia como ponto chave, já que ele é o elo entre o surdo e o universo escolar que na sua maioria é composto por ouvintes. Lacerda (2006) aponta a responsabilidade dada a este profissional, que ultrapassa a prática de traduzir os conteúdos, tendo em vista o objetivo de certificação sobre a compreensão do aluno surdo. Nesses termos, é necessária uma sintonia entre a interpretação e o trabalho dos outros profissionais da equipe envolvidos no processo educativo, com a finalidade de promover não só a escolarização, mas garantir a aceitação do aluno surdo na sala de aula e no universo escolar.

A proposta de educação bilíngue, fundamentada pelos estudiosos da vertente dos Estudos Culturais da Surdez (Perlin, 2006, Skliar, 1997, 2003), por exemplo, aponta para a capilaridade dessa abordagem. $\mathrm{O}$ bilinguismo é uma filosofia educacional que se desdobra nos âmbitos da questão metodológica, linguística, psicolinguística e pedagógica.

Atualmente, inúmeros autores (Lacerda et al., 2013; Merselian, \& Vitaliano, 2011; Stumpf, 2008) e a comunidade surda, discutem a respeito da escola ideal para a implantação efetiva do bilinguismo, considerando que o modelo vigente na escola inclusiva, que se funda na participação do intérprete, tem sido frequentemente questionado por não oportunizar condições coerentes à aprendizagem e ao desenvolvimento desses estudantes. Fatores relacionados à proficiência dos professores em Libras, ao trabalho escolar pautado na língua e à cultura surda são elementos defendidos pelos surdos.

Um trabalho importante realizado por Fernandez e Rios (1998), com parceria da Universidade Estadual do Rio de Janeiro UERJ e do Instituto Nacional de Educação de Surdos INES, se destaca por apresentar, de forma pioneira, um projeto de cunho bilíngue para crianças surdas até 7 anos de idade. Tal projeto teve como objetivo, elaborar um suporte linguístico dentro da escola, para que as crianças atendidas, surdas 
e ouvintes, estabelecessem um comportamento bilingue. As autoras evidenciaram, dessa forma, a necessidade de um sistema educativo que considerasse a condição sine qua non na qual vive o surdo: sujeitos naturalmente diglotas. Isso significa que independentemente do espaço criado para a implantação do bilinguismo escolas exclusivas para surdos ou escolas comuns, é imprescindível que os profissionais estejam cientes que a Libras e a Língua Portuguesa são em níveis diferentes ${ }^{1}$ requisitos básicos, não apenas para a educação dos surdos, mas para a sobrevivência deles em sociedade.

Nessa linha, Lacerda et al. (2013) analisaram a política educacional de alunos com surdez e seu impacto em escolas do município de São Paulo. Esse município possui escolas bilíngues exclusivas para esse público, além da escola regular inclusiva, fato que indica uma tentativa de aproximação sensível aos desejos da comunidade surda ${ }^{2}$. Em contrapartida, o estudo enfatiza que, independentemente do tipo de escola, uma educação de qualidade para os surdos, requer condições concretas de implementação das políticas governamentais para atender as especificidades desse público, isto é, uma escola com planejamento de ações pedagógicas coerentes com os pilares de uma educação bilíngue.

O tratamento dos aspectos pedagógicos tem sido reiteradamente discutido nos estudos concernentes a esse tema, contribuindo para a reflexão e proposição de novos caminhos. O papel do professor, do intérprete, modos de promoção da língua de sinais na escola, bem como o desenvolvimento de metodologias específicas para a aprendizagem dos surdos, são aspectos sinalizados em recentes esforços investigativos (Campello, 2007; Lebedeff, 2010; Sá, 2011).

Campello (2007), por exemplo, descreve o trabalho de uma professora surda que se beneficia da pedagogia visual nos processos de ensino-aprendizagem, traduzindo, de forma geral, a importância de uma reformulação curricular e de uma didática que explore não apenas a imagem, mas uma "semiótica visual na prática educacional cotidiana” (2007, p. 130). A investigação de Campello (2007) foi resultante do projeto de extensão intitulado "Educação de Surdos: professores surdos, professores bilíngues e intérpretes de línguas de sinais" desenvolvida no período de 2003 a 2008, na Universidade Federal de Santa Catarina.

Contudo, apesar das experiências bilíngues supracitadas, ainda não há uma diretriz ou um modelo já consolidado sobre como deve ser a educação de surdos. A sensação dos professores que tem alunos surdos em suas classes, de acordo com Santos (2011), é de limitações na formação para o atendimento desse alunado frente à sua peculiaridade linguística. Esses aspectos, que merecem ser considerados para efetivar um ensino bilíngue de qualidade para os surdos, colocam em destaque todos os profissionais que atuam com esses alunos nas escolas. A partir do contexto de múltiplas facetas e posicionamentos ideológicos contraditórios sobre a inclusão de surdo, vale indagar sobre os posicionamentos dos diversos agentes profissionais atuantes na escola frente à educação dos surdos. Afinal, o que eles dizem a respeito desse processo educacional?

\section{Desafios educacionais da inclusão de surdos: o que dizem os profissionais da escola?}

Como esclarecido anteriormente, a educação de alunos surdos passou por uma fase de conflitos e lutas, especialmente em razão da adoção do bilinguismo como linha norteadora dos processos educativos. Tal filosofia demandou e demanda transformações radicais nos ambientes escolares, na pedagogia desenvolvida, na concepção sobre a surdez, exigindo especificidades formativas dos profissionais que participam desse processo educativo.

Professores, diretores, intérpretes de Libras e orientadores têm sido focalizados em pesquisas (Almeida, 2011; Lacerda, 2006; Lorenzzetti, 2002/2003) que investigam as práticas bilíngues e o impacto da inclusão educacional do surdo, conforme será visto adiante. Considerando os elementos fundamentais para a aprendizagem e o desenvolvimento desse público em sala de aula: língua de sinais, cultura surda, estratégias pedagógicas os educadores teceram críticas sobre o ensino de surdos.

\footnotetext{
${ }^{1}$ A Libras é a língua que possibilita ao surdo brasileiro uma aprendizagem assistemática (no encontro com os pares surdo-surdo), assim como o português é para o ouvinte brasileiro, por isso, a Libras é a mais importante para o processo de aquisição de linguagem e, portanto, nos processos de escolarização do surdo.

${ }^{2} \mathrm{~A}$ comunidade surda requereu a criação de escolas bilíngues exclusivas para surdos. Esse desejo está expresso no documento "A Educação que nós surdos queremos" e é amparado legalmente no Decreto no 52.785, de 2011 (FENEIS, 1999).
} 
Lorenzzetti (2002/2003), por exemplo, investigou a inclusão educacional de surdos a partir da visão de cinco professoras atuantes em classes do ensino fundamental de uma escola localizada no município de Itajaí/Santa Catarina; uma das docentes realizava, no período inverso de suas aulas, orientação educacional de professores da rede regular. A autora pôde constatar, por meio dos relatos das participantes, a dificuldade para elaborar estratégias de ensino para os surdos; fruto do pouco conhecimento sobre as questões pertinentes ao desenvolvimento linguístico dos estudantes. A Libras era identificada como uma possibilidade de comunicação, no entanto, por vezes, as docentes evidenciavam que era difícil manter uma relação direta com o surdo, por causa da diferença linguística; elas não dominavam a língua de sinais e questionavam o fato de os estudantes utilizarem com mais frequência essa língua.

O estudo realizado por Lorenzzetti (2002/2003) trata de um assunto recorrente nas experiências de inclusão escolar: os embates das diferentes culturas e modos de expressão advindos do alunado. Todavia, ao analisar esses conflitos tendo como referência a educação dos surdos, emergem dois pontos importantes: a) a questão da identidade surda, seus modos próprios de se relacionar e apreender o mundo e b) o direito de inserção do surdo nas dinâmicas sociais composta por ouvintes, respeitando sua especificidade cultural sem que, no entanto, esta seja considerada inferior dentro dos estabelecimentos de ensino.

Nessa linha, Lacerda (2006) afirma que a inclusão de surdos é muito benéfica por oportunizar discussões sobre alteridade, elaboração de conceitos sobre a surdez e, de forma geral, problematizações sobre o preconceito presente nas práticas educativas. Entretanto, a autora percebe, a partir de investigações com profissionais envolvidos nessa dinâmica, que esta inclusão não tem sido tão proveitosa para os surdos, como pode ser observado também nos estudos realizados por Quadros (2006) e Stumpf (2008).

Almeida (2011) investigou a concepção de uma professora de biologia e uma diretora sobre o processo de ensino e aprendizagem de alunos surdos incluídos em uma escola pública de Jandira, município de São Paulo. Almeida (2011) constatou que a visão dos profissionais sobre a educação dos estudantes surdos é pautada na ótica integracionista, cujo cerne é a promoção da inserção social, a partir da convivência com os demais estudantes e profissionais da escola. $\mathrm{Na}$ pesquisa, a diretora avalia a inclusão a partir da frequência escolar do estudante surdo. Para a diretora participante da pesquisa, não está clara a distinção entre integração e inclusão, por isso alega que a presença do surdo não gera nenhuma espécie de conflito e que a escola não carece de transformações para atendê-lo, considerando que a oportunidade de matrícula já se delineia como uma vitória para o aluno. Isto reflete dois fatores comuns nas situações de inclusão escolar de estudantes surdos: a) imposição de um modelo escolar que despreza suas especificidades (habitualmente orientado para a maioria ouvinte) e b) concepção da surdez como deficiência; pressupondo uma incapacidade intelectual dos estudantes e elegendo as interações sociais como elementos principais do processo educativo.

O momento atual da educação, que é marcado pela luta política-ideológica das culturas e respeito às singularidades, apresenta conflitos decorrentes do etnocentrismo que engendra a negação do diferente, hierarquizando os modos humanos de se relacionar (Schemberg, 2009). Tal realidade é muito evidente na inclusão escolar do surdo, por isso, investigar esse processo, partindo dos profissionais responsáveis pela formação desses sujeitos, tem sido uma tarefa constante entre os estudiosos dessa área (Guarinello, Berberian, Santana, Massi, \& Paula, 2006; Lacerda, 2006; Schemberg, 2009; Silva, 2014; Tenor, Novaes, Trenche, \& Cárnio, 2009).

Seguindo esse interesse temático, foi feita uma investigação que contemplasse os posicionamentos dos agentes participantes da inclusão do surdo. A investigação abordou as concepções sobre a inclusão escolar, salientando o bilinguismo como princípio orientador desse processo. Tendo em vista que a extensa bibliografia que aborda o tema usualmente se atém aos professores e intérpretes, a pesquisa contemplou todos os profissionais envolvidos diretamente na inclusão de surdos.

Dessa forma, a presente pesquisa focalizou a equipe de profissionais formada por o supervisor pedagógico, a coordenadora da área de humanas, o coordenador da área de exatas, a coordenadora de linguagens e códigos, a diretora, o professor de português como segunda língua, a professora da sala de recursos multifuncionais e o intérprete de Libras de modo a responder as seguintes indagações: Quais sãos os sentidos produzidos acerca do processo de inclusão dos estudantes surdos? O que pensam a respeito do surdo e da surdez? 


\section{Método}

O passo preliminar para efetivar este trabalho foi submetê-lo, em forma de projeto, ao Comitê de Ética em Pesquisa do Instituto de Ciências Humanas da Universidade de Brasília. Com o aval do Comitê, a proposta de pesquisa foi apresentada à diretora da instituição de ensino escolhida. Posteriormente, foi realizado o processo de sensibilização investigativa no qual a pesquisadora aproximou-se da equipe de profissionais da escola.

Para tanto, houve a participação nas reuniões coletivas, semanalmente, durante um mês. O convite e os esclarecimentos éticos concernentes ao sigilo, uso de nomes fictícios, confidencialidade dos dados, riscos e benefícios, acervo dos dados seguindo às regulamentações éticas de pesquisas com seres humanos e disponibilidade do Termo de Consentimento Livre e Esclarecido e de Utilização de Imagem e Voz também foram encaminhados para a equipe formada pelo supervisor pedagógico, a coordenadora da área de humanas, o coordenador da área de exatas, a coordenadora de linguagens e códigos, a diretora, o professor de português como segunda língua, a professora da sala de recursos multifuncionais e o intérprete de Libras.

Com relação a construção dos dados, optou-se pelos pressupostos teóricos do materialismo histórico dialético, que aponta que sujeito e objeto de estudo são compreendidos como instâncias indissociáveis e constituídas nas relações sociais. Pautada nessa lógica, a pesquisa e o tratamento dos dados não podem preterir o caráter eminentemente social e histórico nos quais são elaborados o fenômeno investigativo (Romanelli, 2011).

Nesses termos, o caminho metodológico impõe ao pesquisador a construção de conhecimentos científicos alicerçados aos pilares materialistas, isto é, que obedeça a critérios rígidos para a análise do objeto (homem) em suas condições históricas e objetivas de vida. Sob esse viés, o homem, como dito anteriormente, é um ser social que vive em uma realidade concreta marcada pela cultura e mediada pela linguagem, fator que o distingue de outras espécies animais e constitui sua atividade consciente (Luria, 1991). A linguagem, signo por excelência, é o instrumento de mediação que torna os elementos culturais partilhados entre as pessoas (plano interpsicológico) em produtos internos da mente (plano intrapsicológico), viabilizados pela internalização (conceito Vigotskiano); esse processo sugere a conexão existente entre o meio social e as estruturas psicológicas do homem. Justi- fica-se, portanto, a importância de princípios metodológicos que considerem a "natureza psicológica da pessoa" (p. 205), isto é, “o conjunto das relações sociais” (p. 205) que as constituem (Romanelli, 2011).

Tais relações são arraigadas por tensões políticas, econômicas e culturais que afetam o comportamento dos indivíduos, na medida em que fazem parte da própria formação de suas estruturas mentais de forma singular (ontogênese), ao mesmo tempo em que explicam/compõem o desenvolvimento histórico da espécie humana (filogênese). Para Sirgado (2000), o caráter histórico da abordagem materialista remete a duas questões: a) os modos organizativos da sociedade ao longo do tempo (historicidade do homem social) e b) a dialética geral das coisas. A dialética marxista, aplicada ao método, torna-se um instrumento primordial para a interpretação da realidade em plena concreticidade; uma investigação que centraliza, como dito anteriormente, as condições materiais (contexto político/social/econômico) das quais emergem o objeto de estudo (homem) e que admite as contradições inerentes desse processo. Tendo em vista os principais dessa epistemologia, torna-se imprescindível a aplicação do método comprometido com as leis fundamentais do desenvolvimento psicológico que, imerso na atual sociedade capitalista, encontra nas interpretações marxianas valiosas considerações para a compreensão de diferentes campos do conhecimento.

Para Romanelli (2011), existem duas formas de concepção do método: a primeira diz respeito aos princípios filosóficos gerais que orientam o pesquisador, ou seja, as argumentações sobre o método epistemológico, que é brevemente apresentada aqui sob os fundamentos da epistemologia materialista histórica e dialética. A segunda concerne aos procedimentos técnicos utilizados para alcançar os objetivos da investigação, denominado como método de pesquisa.

No que tange aos procedimentos de análise de dados é importante destacar que foi produzido um texto a partir de dois instrumentos: o primeiro trata das anotações que deu origem ao diário de campo e o segundo é a transcrição literal do material videogravado (entrevistas semiestruturadas). As anotações registraram as percepções gerais da pesquisadora sobre os participantes e as dinâmicas vivenciadas no decorrer da atividade de campo. Os dois instrumentos compuseram uma espécie de portfólio que privilegiou a polifonia da palavra, evitando uma análise monológica do objeto de pesquisa (Amorim, 2013; Romanelli, 2011). 
A entrevista semiestruturada se pautou na formulação de um roteiro geral para orientar a pesquisa. No entanto, a atuação do investigador não ficou restrita às perguntas pré-estabelecidas (Manzini, 2004). Ela abrangeu também o próprio contato com o entrevistado e as reflexões e análises provenientes desse encontro, permitindo a reelaboração de hipóteses relacionadas ao tema de pesquisa.

As entrevistas reunidas para a presente pesquisa formaram um texto no qual a palavra é contemplada como unidade categorial de análise. Por esse viés, apreende-se a circularidade dos discursos dos participantes permitindo a compreensão do jogo de sentidos comuns do processo de produção e interpretação do conhecimento científico, que na composição desse trabalho é articulado as dinâmicas culturais em que os sujeitos estão imersos (Goés, \& Cruz, 2006).

O espaço em que a investigação foi realizada é uma escola inclusiva de ensino médio, da rede pública do Distrito Federal (DF) que possui, aproximadamente, 40 alunos surdos matriculados. As entrevistas foram videogravadas em uma sala isolada nas dependências da escola, tendo uma duração média de 120 minutos cada. Optou-se por realizá-las duas vezes com cada participante. A pesquisa foi subdividida em três momentos:

1. Reunião preliminar com o grupo de profissionais participantes;

2. Realização da primeira etapa de entrevistas com os profissionais individualmente; $\mathrm{e}$

3. Segunda etapa de entrevistas com os profissionais em carácter individual.

No campo buscou-se reconhecer, as percepções dos profissionais sobre: conceitos acerca da surdez e língua de sinais; inclusão de surdos; e desafios da inclusão educacional dos surdos para a escola. Todo o processo ocorreu entre o primeiro e o segundo semestre de 2013. Ao final da coleta de dados, as videogravações foram integralmente transcritas, resultando em um diário de campo analisado cuidadosamente na tessitura deste trabalho. Ao final da produção científica, todas as informações fornecidas pelos participantes foram arquivadas no banco de dados e permanecem sob guarda da pesquisadora principal. Das análises, depreendeu-se um eixo importante acerca dos posicionamentos dos profissionais envolvidos na inclusão educacional do surdo: a concepção dos profissionais da escola sobre o surdo e à surdez.

\section{Resultados e discussão}

\section{Eixo: a concepção dos profissionais da escola sobre o surdo e à surdez}

Ao serem questionados sobre suas trajetórias na educação de surdos, os educadores conceituam a surdez do mesmo modo que distúrbio do processamento auditivo central (DPAC), transtorno de déficit de atenção com hiperatividade (TDAH), surdo-cegueira, e descrevem situações cotidianas relacionadas aos alunos com necessidades especiais. Nesse contexto, a deficiência apareceu como núcleo no qual circulavam os sentidos atribuídos ao estudante surdo, no cenário escolar. A partir daí, os posicionamentos dos profissionais foram revelando conceitos ambíguos sobre a surdez; ora apresentando-a como sinônimo de deficiência, ora desconstruindo-a.

Nessa linha, Vera (diretora), ao descrever uma situação escolar cotidiana, fala sobre o aluno surdo:

Eu tenho que entender que a limitação dele de não falar, não ter a língua dos falantes. Eu tenho que ter um atendimento especial, no sentido de atender por conta dele não ter a linguagem. Mas eu não posso ser paternalista, entendeu? A gente não tem que dar uma proteção especial. Nós temos, que ampliar o conhecimento de Libras na escola, que ele consiga uma autonomia, consiga se virar, não ficar muito dependente, porque aí você promove essa autonomia do surdo. É saber que a limitação dele é a surdez e nada mais.

A opinião de Vera sobre o aluno surdo está ligada à visão de mutismo, isto é, um ser que não fala e que por essa razão, precisa de um atendimento especial em Libras. Fica claro, que a diretora toma a Língua Portuguesa, na modalidade oral, como patamar de comparação e, na ausência dela, existe uma não linguagem.

Igor, supervisor pedagógico, por sua vez, destaca a surdez como fator que distingue o surdo do ouvinte. Ele explica: "O grupo é separado dos outros alunos. Separado pela deficiência, por não conseguirem se comunicar com os outros. Aqueles que são surdos completos, com grande quantidade de deficiência, por exemplo, são ainda mais difíceis". Fica evidente que, para Igor, a diferença do aluno surdo é em razão de ser um indivíduo que não pode ouvir e vive com uma imposição biológica, ou seja, portador de uma falha que dificulta, por exemplo, as trocas linguísticas com o grupo majoritário. 
Os depoimentos de Vera e Igor revelaram uma visão a respeito da surdez: uma deficiência e defeito biológico. Tal visão, segundo Ferraz (2009), baseia-se no modelo médico-terapêutico que fundamentou o olhar patologizante acerca da surdez. Conceituado como anormal, o surdo é compreendido como um sujeito que vive a incapacidade decorrente do defeito de não ouvir. Isso faz com que o surdo ocupe um lugar de inferioridade e menos valia perante o ouvinte; sujeito superior, por ser considerado organicamente completo.

Percebe-se no discurso desses educadores uma eterna busca para aproximar os estudantes surdos no que se refere seus comportamentos, formas de aprender e de interpretar o mundo do modelo ouvinte que engendra a fala, a escuta e a leitura da língua majoritária como elementos imperativos, descaracterizando as especificidades inerentes ao surdo (Perlin, \& Quadros, 2006). Sandra, professora da sala de recursos, relata que um de seus alunos, nas dinâmicas escolares, foi forçado a agir como ouvinte a partir da aprendizagem da língua oral. Contudo, contra argumenta tais procedimentos, pois acredita não ser ideal para o desenvolvimento linguístico e psicológico do surdo:

O Romeu, aluno do segundo ano, escuta e fala um pouquinho... Ele é um estudante surdo que consegue me enganar (referindo-se a habilidade de oralizar, no entanto, eventualmente sem atribuir sentido as palavras porque ele foi oralizado com força. Ele conhece as palavras, ele entende o que a gente está falando. Mas ele é diferente do meu aluno Marcos que ouve parcialmente, sempre ouviu parcialmente. No entanto, ele , Marcos, se desenvolveu na cultura surda, por isso compreende melhor o que as palavras significam dentro de cada contexto... o surdo politizado entende as coisas! Já o Romeu escuta, mas não entende. Muitas vezes, ele Romeu fala assim: - Desculpa professora, mas eu não entendi, o que significa? Aí, eu tenho que explicar para ele igualzinho eu explicava para os outros surdos. Ele foi forçado à oralização.

Amorim (2013) tece argumentações concernentes à forma como o surdo se vê em suas relações com os outros. Nessa direção, constatou-se que o discurso do surdo sobre si mesmo converge para o conceito dele acerca do que supostamente o outro pensa sobre ele. Sendo assim, o discurso dos profissionais envol- vidos com a inclusão de surdos coaduna-se com uma maneira de o surdo se ver na experiência escolar que, aqui, pode ser traduzido por palavras que refletem o olhar estigmatizador frente à surdez: limitação, deficitários, difíceis, lentos, diferentes, deficientes (Campello, 2007; Quadros, 2006).

Graça, coordenadora de humanas, educadora apresentada acima, revela em um momento de sua entrevista, tais interpretações acerca dos surdos. Ela afirma, por exemplo, que a surdez é uma deficiência que compromete a vida escolar e a vida em sociedade. Graça problematiza: Eu entendo a dificuldade da formação do pensamento, eu entendo a dificuldade de tudo isso por causa do sentido. O mundo é auditivo! É muito diferente a construção das conexões intelectuais. O problema é que não se pensa no menino no pós-escola. É uma deficiência tão grande que ele não consegue mais ter um entendimento? $\mathrm{E}$ a vida dele, é como? Então, ele nunca vai ler um livro, um jornal, ele nunca vai entender nada? Ele não tem acesso a isso? Então, onde está a deficiência? Nos profissionais que não alcançam a deficiência dele ou é do pensamento dele?

É interessante constatar que Graça demonstra, em forma de pergunta, uma crítica referente à surdez, calcada na crença de que o fato de não ouvir impõe uma barreira à formação dos processos psíquicos. Isto é, uma falha orgânica que compromete não apenas as possibilidades de socialização da pessoa, mas o desenvolvimento acadêmico. Um estudo realizado com cinco professores que possuíam alunos surdos em suas classes (Guarinello et al., 2006) constatou opiniões semelhantes às observadas nos comentários de Graça.

Nessa linha, os educadores relacionavam os obstáculos escolares aos motivos biológicos surdez, que, de alguma forma, os eximia da responsabilidade em solucionar os problemas da prática educativa. Em uma linha contrária, Sandra afirma que muitos profissionais atribuem aos estudantes o estigma de incapazes por causa da surdez. Ela relembra conversas que circulam nos corredores da escola:

Eu sempre ouvia os professores comentando a falta de alfabetização dos surdos. Comentários meios jocosos, assim meio desprezíveis, por 
exemplo: "nossa, como esse aluno é burro. Nossa, como ele não sabe fazer isso. Nossa, esse aluno não sabe ler". Era sempre "não sabia". Todos os alunos surdos não tinham capacidade para nada. E aquilo me inquietava, eu pensava: "Caramba, olha o jeito que os professores falam dos surdos?!”... Só que eu não conhecia os surdos, não sabia nada sobre eles. Uma coisa é você ouvir falar de alguém, outra coisa é você conhecer.

Como argumentado no aporte teórico (Lacerda, 2006; Lodi, 2005), a inabilidade de aprender, de ser educado ou de possuir condições mínimas para responder por suas atitudes, são marcas da história do surdo, apesar de cientificamente desmistificadas. Nesse sentido, Silva (2014) explica que essa visão não desvencilha o surdo do pressuposto simplista sobre a surdez que faz reverberar os antigos discursos pautados no defeito.

Graça e Igor relatam, em tom de desabafo, que dispensam enorme esforço para atendê-los e educá-los. Decorre desse esforço, um sentimento de frustração que se mantém reavivado por ouvirem, constantemente, às demandas dos professores nas coordenações coletivas referentes ao pouco avanço e/ou (in)compreensão dos surdos sobre os conteúdos apresentados em sala de aula. De fato, parece haver uma grande dificuldade docente no manejo das questões linguísticas, em especial, o Português como segunda língua, que é um conhecimento "extremamente defasado" nos surdos, comentam os educadores pesquisados. Igor relata: "A pouco tempo chegou um professor de segunda língua que a gente chama né".

Igor fala, referindo-se ao professor de português como segunda língua, que os outros profissionais também já tinham dito isso e agora ele também estava verificando que alguns alunos surdos conseguem, outros não conseguem acompanhar o português como segunda língua. O professor de português como segunda língua até comentou: "Olha, alguns alunos surdos se você quiser, nem precisam mais ficar na sala de segunda língua, já conseguem acompanhar o professor com intérprete na sala de aula, mas tem surdos que estão extremamente defasados, praticamente analfabetos".

Para eles, a "defasagem" dos alunos está estritamente ligada à surdez, focalizando o não ouvir. Contudo, sabe-se que a surdez, por si, não se constitui como impedimento para o aprendizado de outra língua. Conforme destacado por Lodi (2005) e Lacerda (2006), a peculiaridade linguística é a chave explicativa para compreensão do papel da língua de sinais e da comunidade surda no desenvolvimento e constituição do surdo. Nesse contexto, Vitória, intérprete de Libras, explica:

Eu pensava que o surdo não podia abarcar o meu modo de interpretar o mundo, pensava que o meu domínio era uma coisa que ele não tinha. Mas, aí, é claro, eu saí dessa visão do "o que ele não tem" e entendi que, enquanto sujeito, pessoa, ele tem uma especificidade linguística que o torna pleno. Só que nada disso é respeitado na escola. Eles acreditam que incluir o surdo é jogar a Libras na escola, mas sabemos que é muito mais do que isso... É preciso respeitar a especificidade linguística, trazer a escola e os profissionais para dentro de todo um contexto diferenciado de cultura e de aprendizagem... É essa parte que é ignorada no processo.

Vitória e Sandra destacam, em seus depoimentos que o surdo apreende o mundo de modo distinto, se comparado com o aluno ouvinte. No entanto, ele é capaz de se desenvolver plenamente, tal como a maioria (ouvinte), se suas particularidades forem captadas/respeitadas pelos educadores. Ademais, sabe-se que o modo como os educadores percebem o surdo e suas particularidades é determinante para a elaboração de estratégias pedagógicas e condução do processo educativo.

\section{Conclusão}

A concepção dos profissionais sobre o aluno surdo e a surdez, objeto investigado na presente pesquisa, trouxe à tona questões sobre as demandas culturais, linguísticas e pedagógicas. Tal debate está situado nas interfaces entre Psicologia e Educação, haja vista a singularidade dos processos simbólicos dos estudantes (que se constituem na língua de sinais) e o reflexo dessa condição no campo educativo.

Como visto na análise, a condição bilíngue e bicultural traz exigências que, se desprezadas, acarretam prejuízos para o desenvolvimento acadêmico, comprometimentos cognitivos e desdobramentos sérios para a vida do surdo como, por exemplo, o não empoderamento e desvantagens nas relações sociais. 
Além disso, a pesquisa revelou o modo como a inclusão educacional tem sido conduzida, considerando os processos de formação dos profissionais do Distrito Federal (DF), que merecem atenção e discussões mais aprofundadas. Percebeu-se que há uma lacuna na formação conceitual sobre a surdez, o surdo e a língua de sinais nos quais estão situados e marginalizados os maiores problemas de ordem pedagógica. Essas lacunas estão diretamente ligadas ao modo como as políticas públicas têm priorizado (ou não) os processos formativos dos professores. Há uma distância entre o que as diretrizes governamentais deliberam e o que acontece na sala de aula.
Os fatores levantados nesse empreendimento investigativo refletem a necessidade de revisão das práticas educacionais e as condições às quais estão pautadas a inclusão dos estudantes. A formação bicultural e bilíngue de surdos, diante das constatações da presente pesquisa, precisa ser reconhecida e colocada em prática na escola. Para tanto, profissionais e comunidade escolar devem compreender que a língua e a cultura surda não são apenas mecanismos para incluí-lo; tais elementos constituem a identidade dos surdos. O desprezo e negligência à essa singularidade dentro da escola compromete as possibilidades de aprendizagem e desenvolvimento pleno dos estudantes.

\section{Referências}

Almeida, K.S. (2011). A inclusão de um aluno surdo no Ensino Médio de uma escola da Rede Estadual Regular (Monografia não publicada). Centro de Ciências Biológicas e da Saúde, Universidade Presbiteriana Mackenzie, São Paulo, SP, Brasil.

Amorim, A. C. F. (2013). Surdez e biculturalidade: Um estudo sobre o autoconceito a partir das interações surdo-surdo e surdo-ouvinte (Dissertação de mestrado). Universidade de Brasília, Brasília, DF, Brasil

Beltrami, C. M., \& Moura, M. C. (2015). A educação do surdo no processo de inclusão no Brasil nos últimos 50 anos (1961-2011). Revista Eletrônica de Biologia, 8(1), 146-161.

Campello, A. R. S. (2007). Pedagogia visual/sinal na educação dos surdos. In R. M. Quadros; \& G. Perlin (Eds.), Estudos surdos II (pp. 100-131). Petrópolis, RJ: Arara Azul.

Dizeu, L. C. T. B., \& Caporali, S. A. (2005). A Língua de Sinais constituindo o surdo como sujeito. Educação \& Sociedade, 26(91), 583-597. https://doi.org/10.1590/S0101-73302005000200014

Federação Nacional de Educação e Integração dos Surdos - FENEIS. (1999, abril de 1999). Que educação nós surdos queremos. Pré-congresso ao V Congresso Latino Americano de Educação Bilíngüe para Surdos, Porto Alegre, Rs, Brasil, 5.

Fernandes, S. \& Moreira, L.C. (2009). Desdobramentos politico-pedagógicos do bilinguismo para surdos: reflexões e encaminhamentos. Revista de Educação Especial, 22(34), 225-236.

Fernandez, E., \& Rios, K. R. (1998). Educação com bilingüismo para crianças surdas. Intercâmbio, 3, 13-21.

Ferraz, R. A. (2009). O mundo surdo: Passeata dos surdos: Luta e comemoração (Monografia). Faculdade Santa Helena, Recife.

Garcia, R. M. C. (2013). Política de educação especial na perspectiva inclusiva e a formação docente no Brasil. Revista Brasileira de Educação, 18(52), 101-119. http://dx.doi.org/10.1590/S1413-24782013000100007

Góes, M. C. R., \& Cruz, M. N. (2006). Sentido, significado e conceito: Notas sobre as contribuições de Lev Vigotski. Pro-Posições, 17(50), 31-45.

Góes, M. C. R. \& Lacerda, C. B. F. (2000). Surdez: Processos educativos e subjetividade. São Paulo, SP: Lovise.

Goldfeld, M. (2002). A criança surda: Linguagem e cognição numa perspectiva sociointeracionista. (3a ed.). São Paulo: Plexus.

Guarinello, A. C., Berberian, A. P., Santana, A. P., Massi, G., \& Paula, M. D. (2006). Deaf student insertion in regular schools: Deaf teachers from Parana State views. Revista Brasileira de Educação Especial, 12(3), 317-330. https:// doi.org/10.1590/S1413-65382006000300003

Kassar, M. D. C. M. (2011). Educação especial na perspectiva da educação inclusiva: Desafios da implantação de uma política nacional. Educar e Revista, (41), 61-79. https://doi.org/10.1590/S0104-40602011000300005

Kelman, C. A., Silva, D. N. H., Amorim, A. C. F., Monteiro, R. M. G., \& Azevedo, D. C. (2011). Surdez e família: Facetas das relações parentais no cotidiano comunicativo bilíngue. Linhas Críticas, 17(33), 349-365. 
Kubaski, C., \& Moraes, V. P. (2009). O bilingüismo como proposta educacional para crianças surdas. Congresso Nacional de Educação-EDUCERE-III Encontro Sul Brasileiro de Psicopedagogia, Curitiba, PR Brasil, 9.

Lacerda, C. B. F. (2006). A inclusão escolar de alunos surdos: O que dizem alunos professores e intérpretes sobre esta experiência. Educação \& Sociedade, 26(69), 163-184. https://doi.org/10.1590/S0101-32622006000200004

Lacerda, C. B. F., Albres, N. A., \& Drago, S. L. S. (2013). Política para uma educação bilíngue e inclusiva a alunos surdos no município de São Paulo. Educação e Pesquisa, 39(1), 65-80. https://doi.org/10.1590/S151797022013000100005

Lebedeff, T. (2010). A educação dos surdos na região do planalto médio rio-grandense: Uma problematização das condições lingüísticas e de escolarização. Anais da Reunião Anual da Anped "Educação No Brasil: O Balanço de uma Década" Caxambú, MG, Brasil, 3.

Lei $\mathrm{N}^{\circ}$ 10.436, de 24 de abril de 2002. (2202, 25 abril). Dispõe sobre a língua brasileira de sinais - Libras - e dá outras providências. Diário Oficial da União.

Lei $N^{\circ}$ 9.394, de 20 de dezembro de 1996. (1996, 23 dezembro). Estabelece as diretrizes e bases da educação nacional. Diário Oficial da União.

Lodi, A. C. B. (2013). Educação bilíngue para surdos e inclusão segundo a Política Nacional de Educação Especial e o Decreto no 5.626/05. Educação e Pesquisa, 39(1), 49-63. https://doi.org/10.1590/S1517-97022013000100004

Lodi, A.C.B. (2005). Plurilinguismo e surdez: uma leitura bakhtiniana da história da educação dos surdos. Educação e Pesquisa, 31(3), 409-424. https://doi.org/10.1590/S1517-97022005000300006

Lopes, E. S., Silvana, F. S. S., Vieira, A. C. C., \& Oliveira, G. F. (2016). Políticas públicas e organizações na educação do surdo. Revista de Psicologia, 10(32), 228-244. https://doi.org/10.14295/idonline.v10i32.588

Lorenzetti, M. L. (2002/2003) A inclusão do aluno surdo no ensino regular: a voz das professoras. Revista Espaço, 18/19, p. 63-69.

Luria, A. R. (1991). A atividade consciente do homem e suas raízes Histórico-Sociais. In A. R. Luria, As raízes histórico-culturais da consciência (2a ed., pp. 71-84, Curso de psicologia geral, vol. 1). Rio de Janeiro, RJ: Civilização Brasileira.

Manzini, E. J. (2004) Entrevista semiestruturada: Análise de objetivos e de roteiros. Seminário Internacional de Pesquisa e Estudos Qualitativos em Debate, Bauru, SP, Brasil.

Merselian, K. T., \&Vitaliano, C. R. (2011). Análise das condições organizadas em uma escola para promover a inclusão de alunos surdos. Revista Lusófona de Educação, (19), 85-101.

Perlin, G. (2006). A cultura surda e os intérpretes de língua de sinais (ILS). Revista Educação Temática Digital, 7(2) 136-147. https://doi.org/10.20396/etd.v7i2.798

Perlin, G., \& Quadros, R.M. (2006). Ouvinte: O outro do ser surdo. In R. M. Quadros (Org.), Estudos Surdos I- parte $A$ (Cap. 5, pp. 165-166, Série Pesquisas). Petrópolis, RJ: Arara-Azul.

Quadros, R.M. (2006). Políticas lingüísticas e educação de surdos em Santa Catarina: Espaço de negociações. Educação \& Sociedade, 26(69), 141-161. https://doi.org/10.1590/S0101-32622006000200003

Quadros, R. M. (2003). Situando as diferenças implicadas na educação de surdos: Inclusão exclusão. Florianópolis: Ponto de Vista.

Ribeiro, C. B. (2014). Narrativas e processos de desenvolvimento bicultural: trajetórias escolares de surdos jovens e adultos (Dissertação de Mestrado). Universidade de Brasília, DF, Brasil.

Romanelli, N. (2011). A questão metodológica na produção vigotskiana e a dialética marxista. Psicologia em Estudo, 16(2), 199-208.

Sá, N. R. L. (2011). Escolas e classes de surdos: opção político-pedagógica legítima. In: N. R. L. Sá (Org.), Surdos: Qual escola? (pp. 17-62). Manaus, AM: Valer e Educa.

Sacks, O. (2010). Vendo vozes: Uma viagem ao mundo dos surdos. São Paulo, SP: Companhia das Letras.

Santana, A. P., \& Bergamo, A. (2005). Cultura e identidade surdas: Encruzilhada de lutas sociais e teóricas. Educação \& Sociedade, 26(91), 565-582. https:// doi.org/10. 1590/S0101-73302005000200013

Santana, A.P. (2007). Surdez e linguagem: Aspectos e implicações neurolinguísticas (2a ed.). São Paulo, SP: Plexus. 
Santos, K. R. O. R. P. (2011). Formação continuada e necessidades formativas de professores na educação de surdos da rede pública da cidade do Rio de Janeiro (Tese de Doutorado). Universidade Metodista de Piracicaba, São Paulo, Brasil.

Schemberg, S. (2009). Educação escolar e letramento de surdos: Reflexões a partir da visão de pais e professores. Revista da Sociedade Brasileira de Fonoaudiologia, 14(3), 437.

Silva, C. M. S (2014). Processos de escolarização do Distrito Federal: O que dizem os profissionais da escola sobre a inclusão de surdos? (Dissertação de Mestrado). Universidade de Brasília, Brasília, DF, Brasil.

Silva, C. M., \& Silva, D. N. H. (2016). Libras na educação de surdos: o que dizem os profissionais da escola?. Psicologia Escolar e Educacional, 20(1), 33-44. https://doi.org/10.1590/2175-353920150201917

Silva, C. M., Silva, D. N. H., \& Silva, R. C. (2013). Inclusão e processos de escolarização: Narrativas de Surdos sobre estratégias pedagógicas docentes. Psicologia em Estudo, 19(2), 261-271. https://doi.org/10.1590/1413737222245009

Sirgado, A. P. (2000). O social e o cultural na obra de Vigotski. Educação \& Sociedade, 21(71), 45-78. https://doi. org/10.1590/S0101-73302000000200003

Skliar, C. (Ed.). (1997). Educação \& exclusão: Abordagens sócio-antropológicas em educação especial. 5a ed. Porto Alegre, RS: Mediação.

Skliar, C. (2003). Perspectivas políticas e pedagógicas da educação bilíngüe para surdos. Campinas, SP: Mercado das Letras.

Slomski, V. G. (2010). Educação bilíngue para surdos: Concepções e implicações práticas. Curitiba, PR: Juruá.

Soares, L. R., Andrade, D. J., \& Soares, L. R. (2016). Educação inclusiva dos educandos com surdez em escolas bilíngues ou regulares. Revista Fórum, (34), 105-117.

Souza, R. M. (2003). Intuições “lingüísticas” sobre a Língua de Sinais, nos séculos XVIII e XIX, a partir da compreensão de dois escritores surdos da época. DELTA: Documentação de Estudos em Lingüística Teórica e Aplicada, 19(2), 329-344.

Stumpf, M. R. (2008). Mudanças estruturais para uma inclusão ética. In: R. M. Quadros, Estudos Surdos III (pp. 14-29). Petrópolis, RJ: Arara Azul.

Svartholm, K. (2014). 35 anos de educação bilíngue de surdos - e então?. Educar em Revista, (spe-2), 33-50. https:// doi.org/10.1590/0104-4060.37228

Tenor, A. C., Novaes, B. C. C., Trenche, M. C. B., \& Cárnio, M. S. (2009). A inclusão do aluno surdo no ensino regular na perspectiva de professores de um município de São Paulo. Distúrbios da Comunicação, 21(1), 7-14.

Thoma, A.S., \& Klein, M. (2010). Experiências educacionais, movimentos e lutas surdas como condições de possibilidade para uma educação de surdos no Brasil. Cadernos de Educação, (36), 107-131.

\section{Carine Mendes da Silva}

Pedagoga. Mestre em Psicologia do Desenvolvimento Humano e doutoranda do Programa de Pós-graduação em Processos de Desenvolvimento Humano e Saúde do Departamento de Psicologia Escolar e do Desenvolvimento do Instituto de Psicologia da Universidade de Brasília (UnB).

E-mail: carine_gnt@hotmail.com

\section{Rosa Monteiro}

Pedagoga. Mestre em Psicologia do Desenvolvimento Humano e doutoranda do Programa de Pós-graduação em Processos de Desenvolvimento Humano e Saúde do Departamento de Psicologia Escolar e do Desenvolvimento do Instituto de Psicologia da Universidade de Brasília (UnB).

E-mail: rosamonteiro.rosamonteiro@gmail.com 
Danielle Sousa da Silva

Psicóloga. Doutoranda do Programa de Pós-graduação em Processos de Desenvolvimento Humano e Saúde do Departamento de Psicologia Escolar e do Desenvolvimento do Instituto de Psicologia da Universidade de Brasília (UnB).

E-mail:dssfatima@gmail.com

Daniele Nunes Henrique Silva

Professora do Instituto de Psicologia da Universidade de Brasília (UnB).

E-mail: daninunes74@gmail.com

Endereço para envio de correspondência:

SHCES 207 BLOCO C APARTAMENTO 205 CEP - 70650273 Brasília-DF

Recebido 05/07/2017

Aprovado 16/05/2018

Received 07/05/2017

Approved 05/16/2018

Recibido 05/07/2017

Aceptado 16/05/2018

Como citar: Silva, C. M., Monteiro, R., Silva, D. S., Silva, D. N. H. (2018). Inclusão escolar: Concepções dos profissionais da escola sobre o surdo e a surdez. Psicologia: Ciência e Profissão, 38(3), 465-479.

https://doi.org/10.1590/1982-37030002652017

How to cite: Silva, C. M., Monteiro, R., Silva, D. S., Silva, D. N. H. (2018). School inclusion: Conceptions of school professionals about the deaf and the deafness. Psicologia: Ciência e Profissão, 38(3), 465-479. https://doi.org/10.1590/1982-37030002652017

Cómo citar: Silva, C. M., Monteiro, R., Silva, D. S., Silva, D. N. H. (2018). Inclusión escolar: Concepciones de los profesionales de la escuela sobre el sordo y la sordera. Psicologia: Ciência e Profissão, 38(3), 465-479. https://doi.org/10.1590/1982-37030002652017 